\title{
Interactive comment on "Characterization of atmospheric aerosol optical properties based on the combined use of a ground-based Raman lidar and an airborne optical particle counter in the framework of the Hydrological Cycle in the Mediterranean Experiment - Special Observation Period 1" by Dario Stelitano et al.
}

Anonymous Referee \#3

Received and published: 24 December 2018

This paper deals with the combined analysis of an optical particle counter deployed on airplane and lidar with the objective of providing aerosol typing at different altitudes. The topic is sounds and deserve a publication. The paper is also generally well-written and structured, although eventually lack of consistent scientific conclusions about the method proposed. Before recommending the manuscript publication I have several 
issues that needs to be addressed.

\section{MAJOR CONCERNS}

AMTD

My main concern is about the conclusions obtained in both studies cases when aerosol loads is very low, which is observed in the free troposphere for your study cases. Authors should address this limitation of their methodology by for example doing sensitivity tests using synthetic data. Such analysis will help to better understand the differences you obtain in your analyses.

It is necessary to improve the methodology section about how you obtain different aerosol types from the fitting procedure you propose. It is not clear to me what aerosol parameters you are obtaining. I would recommend adding references to Table 1.

It is not clear to me the capabilities of BASIL and what you are actually using. You say that they are capable of obtaining independent extinction and backscattering at 355 and $532 \mathrm{~nm}$ by Raman technique. But at some points in the manuscript you mention that you use only elastic signals at $532 \mathrm{~nm}$. If this is true, it means that you are using the classical Klett method for obtaining backscattering method that imply constant lidar ratios and thus homogenous aerosol in the entire column. What is then the sense of applying your methodology for aerosol typing? This question is also applicable for backscttering at $1064 \mathrm{~nm}$.

The two study cases are not very different. The area is usually affected by Saharan dust transport. The paper will definitly gain more interest if an study case affected by dust transport is included.

\section{MINOR CONCERNS}

Why using HYSPLIT at different altitues between the two examples? Please unify criterion. There should not be dramatical changes in your interpretation.

I agree with the previous referee about the interpretation of marine aerosol at high levels for the case study on 13th September 2012. See my previous comments about

Interactive comment 
the applicability of your methodology for very low aerosol loads.

Lines 30-35: Please provide references.

AMTD

Line 164: 'particles at higher altitudes are internal mixtures of...' It is impossible to know if they are internal or external mixtures with the instrumentation and methodology you used. Please correct.

Interactive

comment

Figure 1 needs improvements as in its current form does not provides any information. Why not include flight tracks?

What are the effects of incomplete overlap in your methodology?

Line 325-326. 'decreasing number concentration of the same aerosol type (Continental/Urban) as a result of the progressive attenuation of the underlying convective activity' I do not understand this sentence. Please clarify. Conclusions must be improved. What is the added value of your methodology? Under which circunstances is applicable? Which aerosol properties are you providing?

Interactive comment on Atmos. Meas. Tech. Discuss., doi:10.5194/amt-2018-268, 2018. 